\title{
The Effectiveness of Human Patient Simulator on Knowledge, Motivation, and Clinical Competence of the Student's Nursing about Diabetic Ketoacidosis Management
}

\author{
Hotma Rumahorbo*, Haris Sofyana, Kartini M. Ali \\ Politeknik Kesehatan Bandung, Bandung, Indonesia \\ Email: *Hotma_rumahorbo@yahoo.com, hsofyana@yahoo.co.id, kartini.ali21@yahoo.com
}

How to cite this paper: Rumahorbo, H., Sofyana, H. and Ali, K.M. (2018) The Effectiveness of Human Patient Simulator on Knowledge, Motivation, and Clinical Competence of the Student's Nursing about Diabetic Ketoacidosis Management. Open Journal of Nursing, 8, 567-579.

https://doi.org/10.4236/ojn.2018.88042

Received: June 19, 2018

Accepted: August 25, 2018

Published: August 28, 2018

Copyright $\odot 2018$ by authors and Scientific Research Publishing Inc. This work is licensed under the Creative Commons Attribution-NonCommercial International License (CC BY-NC 4.0). http://creativecommons.org/licenses/by-nc/4.0/

\begin{abstract}
Purpose: This study aimed to evaluate the effects of human patient simulator to improve the knowledge, motivation, and clinical competence of the students of Nursing about Diabetic Ketoacidosis (DKA) Management. Methods: The population of this research is the Students of Diploma III Keperawatan Poltekkes Bandung, Indonesia, who was attending Medical Surgical Nursing subject, one of which learning focus is about Diabetic Ketoacidosis. The research subjects were divided into 3 groups, Full SBL (a group of SBL learning with HPS), Semi SBL (a group of SBL model with Partial Task Trainer Simulation), and Conventional model. The overall sample of the research for the three groups is 90 people. Results: The analysis shows significant result with the Kruskal Wallis test. Followed by the Post Hoc test Mann Whitney test, the result shows that the treatment of Full SBL is better than Semi-SBL and Conventional model for knowledge (40.00 vs. 27.00 vs. 35.00 ), motivation ( 74.67 vs. 73.33 vs. 73.00 ), and clinical competence (79.00 vs. 56.50 vs. 76.00). Conclusion: The result of the research shows the effectiveness of the Human Patient Simulator towards the improvement of Knowledge, Motivation, and Clinical competence of the Students of Nursing about DKA management. In addition, the research found that Full SBL improves Knowledge, Motivation and Clinical competence better than Semi SBL and Conventional model.
\end{abstract}

\section{Keywords}

Diabetic Ketoacidosis, Knowledge, Motivation, Clinical Competence 


\section{Introduction}

Diabetic ketoacidosis (DKA) is a life-threatening complication of diabetes mellitus, most common in patients with type 1 diabetes in particular due to a deficiency or absence of insulin [1]. DKA is characterized by three major signs of hyperglycaemia, metabolic acidosis and ketosis and a significant risk of morbidity and mortality [2]. The survival of DKA patients depends on the success of the action of rehydration, correction of metabolic acidosis, insulin administration, electrolyte damage correction, especially hypokalemia and precipitant treatment [3] so that the competence of the medicalteam becomes very important. Nursing students as prospective nurses should be prepared and equipped with competence in handling DKA. Studying complex competencies such as DKA is not easy, considering DKA is very threatening to patients and fast and precise action becomes very important [2]. Knowledge and skills to combine, including leadership, communication, teaching, and research, are urgently needed in their practice to improve patient care so that learning using a simulation approach is essential [1]. Simulations in medicine and nursing have become an important part of student education and practicing health care providers [4].

In Indonesia, the nursing education curriculum is a competency-based curriculum, one of which is the competence of students in handlingemergency patients, including the handling of patients with DKA [5]. The curriculum implementation uses various approaches, such as learning by lecture, simulation, laboratory practice, clinical practice and combination of those. Learning laboratory practice is part of the student's clinical learning cycle [5]. This lesson resembles a clinical condition with a simulation taught by competent teachers.

A good learning media which is used in learning the clinical practice of nursing students is the Human Patient Simulator [6] [7], one of the models that is widely used in clinical competence-based learning [4] [8]. Although the HPS simulation learning is one of the ideal answers to achieve students' clinical competence [9] and it is one of the most comprehensive and innovative learning models [10] [11], the effectiveness of HPS on knowledge, motivation, and clinical competence of nursing students, especially in DKA management has never been reported. The main advantage of using HPS is that it offers students an interactive nursing experience with a variety of health conditions and critical incidents in a real-world environment that "safely" simulates [12]. To date, the application of HPS learning model in nursing education in Indonesia is still relatively limited. The HPS learning model aims to improve the clinical competence from a series of innovative learning experiences and to present the real situations that the nurses face in nursing services [7] [10] [11] [12]. Specific nursing education in Indonesia should pay more attention to the use of HPS in Simulation-Based Learning (SBL). The implementation of this learning model is in line with the development of science and technology as well as the clinical competence of Indonesian nurses [5]. 
Based on the observation, SBL learning model is still limited to partial task trainer simulation which prioritizes on strengthening the cognitive aspect. Clinical competence on the affective and psychomotor aspects in integrative simulation learning in SBL has not been fully implemented due to the lack of HPS learning and the absence of competent teachers [11] [13].

SBL is a simulation-based learning as a way of learning presentation by demonstrating or displaying to the students a particular process, situation or object being studied, both actual and artificial which is often accompanied by oral explanation [14]. Simulation as a model of practical learning that develops students' skills (cognitive or skill domains) [8], by moving a real situation into the learning room activity due to practicing difficulty or limitation in the real situation [11] [15]. Another learning model is the Partial Task Trainer. The partial task trainer model is a simulated learning model that uses simple props and the use of certain pieces of props. This model can be done for procedural learning practices in which the study of students' clinical competence being observed is psychomotor [16].

Standardized Patients: This simulation method uses patients as a simulation model as well as a simulation tool. The standardized patient simulation model is more real because it uses healthy humans treated as simulated patients. This method is good for practical learning that explores the communication skills of learners. However, it has weaknesses when it is applied to clinical cases that require the presenceof the pathological condition of the patients so that the signs and symptoms of the case presented cannot be simulated [17].

Human Patient Simulator: This type of simulation utilizes a patient simulation in the form of mannequins/dolls with the ability to resemble the real conditions of the physiological system of the human body, so that it has a high level of trust resulting in a conducive interaction and learning experience for students [10]. Moreover, the utilization of HPS simulation model is good in exploring students' critical thinking skills, training the accuracy of clinical decision making and inter-professional relationships involved in the treatment of clinical cases [9] [11] [18]. The HPS model demands an interactive practice learning process and provides learning experience to the students. In addition, the utilization of HPS with a high level of trust in the learning process requires the availability of competent instructors/ lecturers with high financial capabilities/cost.

The application of student learning in the management of DKA patients is conducted to find out how effective the HPS model is on knowledge, motivation, and clinical competence of the Nursing students. DKA is one of the tools in applying SBL learning model with HPS, so that the clinical skill that must be possessed by nursing students in Indonesia becomes optimal. The selection of DKA clinical competence is based on the consideration of difficulty and complexity level of DKA problems and students' learning condition in a real situation in treating DKA patients in hospital [19] [20]. Thus, the SBL learning model in the treatment of DKA patients hopefully can be the first step in the application of 
SBL learning model based on HPS on student learning in order to improve knowledge, motivation, and clinical competence of the Nursing students [21] [22].

Based on the above, this research was conducted to find out the Effectiveness of Human Patient Simulator against Knowledge, Motivation, and Clinical competence of the Nursing Students on diabetic ketoacidosis management. Moreover, the research was conducted to find out how significant the influence of different learning models: Full SBL, Semi SBL, and Conventional model, toward knowledge, motivation, and clinicalcompetence of the Nursing students.

\section{Methods}

\subsection{Study Design}

The research was organized as quasi-experiment with a control group. The main purpose of the study was to evaluate the effects of the human patient simulator to improve the knowledge, motivation, and clinical competence of the Nursing students on diabetic ketoacidosis management.

\subsection{Population and Sample}

The population of this research was nursing students in Bandung, Indonesia who are taking the subject of medical-surgical nursing, in which one of the focuses of learning is about diabetic ketoacidosis. The nursing students were divided into 3 groups. Group I was treated with Full SBL (group learning is SBL learning with HPS), Group II was given Semi SBL (group learning is SBL model with partial task trainer simulation), and Group III was a Conventional learning group. The sample size was calculated based on differences in mean scores on knowledge, motivation, and clinical competence on learning with SBL.

The minimum sample size for each group was 26 students, plus the possibility of drop-out by $10 \%$ so that the overall research sample for the three groups was 90 people.

\subsection{Research Procedure}

The data were collected through the demographic information form, knowledge assessment form, motivation assessment form and checklist observation clinical competence. Questionnaires to measure knowledge used 20 question items. Validity and reliability were tested. The Cronbach alpha was 0.92 . The Questionnaire to measure motivation used questionnairesonstudents'motivation toward science learning (SMTSL) developed by Hsiao-Lin-Tuan and was approved for use in this study [23]. A-5 point Likert scale from "most agree to do not agree" was used to assess the motivation. The inventory comprised of 30 positive questions. The Cronbach alpha was 0.96. The instrument used in measuring clinical competence was a standardized instrument [5].

The research implementation on the three groups was supervised by 4 lecturers/instructors in each research group. 
Group I was given Full SBL. The Full SBL was conducted by 4 instructors/lecturers of medical-surgical nursing who have been trained and assisted during the training so that they are skilled in using Full SBL learning. Both instructors/lecturers and students were equipped with learning modules that had been developed according to the objectives and learning steps.

Group II was given Semi SBL. The Semi SBL was conducted by 4 instructors/lecturers of medical-surgical nursing who had been giving the lesson on student clinical competence by using laboratory tools equipped with action standard operating procedure (SOP).

Group III was given the Conventional model. The Conventional model was conducted by 4 instructors/lecturers of medical-surgical nursing who had been giving the lesson on student clinical competence by using learning method of lecturing, discussion, laboratory practice, and using students as patients.

This research was conducted for 6 months by implementing learning module consisting of 4 Learning Activities (KB), as follows:

KB 1: It contains the General Concept of DKA.

The material presented in $\mathrm{KB} 1$ was related to the basic concept of DKA, perspective and issue of Diabetes Mellitus (DM) in Indonesia. The basic concept of DKA encompasses the notion of DKA, the factors that cause DKA, pathophysiology, and the signs and symptoms that arise in DKA patients [20] [21]. Expected result from $\mathrm{KB} 1$ is that instructors/lecturers can recall the process of DKA incidence and its impact on the body system and actions that must be immediately given to the patient.

KB 2: It contains concepts and standards for Treating DKA Patients.

KB 2 contains materials related to the management of patients with DKA and the monitoring of patients with DKA. The management of DKA patients refers to the DKA management standard [22] [24]. Furthermore, the monitoring of DKA patients refers to the SOP applied in hospitals [19] [25]. Nursing lecturers are expected to understand the flow of DKA patient management based on algorithm. [24] [25]. For the management of patient further study is needed and referral criteria need clarifying. Using the protocol and specialist services is the standardizedinitial management and does help to optimise management [26].

KB 3: It contains the General Concept of Model Simulation-Based Learning (SBL).

The SBL model as one of the comprehensive and innovative learning models is one learning model which presents real situations into the learning environment in the classroom/room, thereby providing an appropriate learning experience according to the expected clinical competence [9]. Simulation-Based Learning (SBL) uses HPS as practical learning media by presenting the real situation supported by various other learning tools. Practical learning is systematically designed through case scenarios integrated into HPS mannequins/dolls, resulting in real situations that can show the actual clinical condition that must be mastered by the students [10]. In the simulation of this model, the direct use 
of patients to explore communication skills, ethics and other aspects can be obtained by presenting the role of the patient (a patient simulator) in the form of the patient's family to support the HPS that has been set into a computer device. The SBL model consists of pre-briefing, setting introduction, simulation briefing, theory input, case briefing, case scenario, debriefing, and ending [13].

KB 4: It contains SBL Implementation in Treating DKA Patients.

These learning activities contain a series of learning processes using a simulation model based learning. The learning stages start from the initial structuring of the learning environment, simulator briefing, input theory, scenario briefing, simulation process, debriefing and end with simulation closing [10].

\subsection{Data Analysis}

Measurement of knowledge, motivation and clinical competence of the subjectwas conducted before and after treatment for 6 months. Normality test was performed on the collected data namely knowledge, motivation and clinical competence. Normality test results showed that the data were not normally distributed so that non-parametric analysis was used with Kruskal Wallis test and followed by Post Hoc analysis with Mean Whitney. A $p$ less than 0.05 was considered statistically significant.

\section{Results}

The result of research data on knowledge, motivation and clinical competence after being given Full SBL Model, Semi-SBL Model, and Conventional Model for the nursing students are listed in Table 1 . Since the data were not normally distributed, the Kruskal Wallis test was followed by analysis of Post Hoc with Mann Whitney to know how significant the influence of Full SBL, Semi SBL and Conventional model to the changes of knowledge, motivation and clinical competence of the Nursing students was, and the result is in Table 1 and Table 2.

The analysis showed that Kruskal Wallis test result was significant. Followed by the Post Hoc test with the Mann Whitney test at CI 95\%, the result showed Full SBL treatment was better than Semi SBL and Conventional on knowledge (40.00 vs. 27.00 vs. 35.00 ), motivation (74.67 vs. 73.33 vs. 73.00 ), and clinical competence (79.00 vs. 56.50 vs. 76.00). Post Hoc analysis with Mann Whitney test is shown in Table 2. For more details, the data analysis results are shown in Figures 1-3.

\section{Discussion}

\subsection{The Influence of Full SBL, Semi SBL and Conventional Learning Model to the Knowledge Improvement of the Nursing Students}

The research result showed that there was a better improvement of knowledge with the provision of Full SBL learning model compared to Semi-SBL and Conventional model (knowledge (40.00 vs. 27.00 vs. 35.00 ). The three instructional 
Table 1. Differences in knowledge, motivation and clinical skills in full-SBL model group, semi-SBL model group and conventional model group of the students of nursing about DKA management.

\begin{tabular}{|c|c|c|c|c|c|}
\hline Variable & Group & $\mathrm{N}$ & Median & Min-Mak & $p^{*}$ \\
\hline \multirow{3}{*}{$\begin{array}{l}\text { Pre Intervention } \\
\text { Knowledge }\end{array}$} & Conventional & 30 & 30.00 & $15.00-50.00$ & 0.364 \\
\hline & Semi SBL & 30 & 30.00 & $15.00-40.00$ & \\
\hline & Full SBL & 30 & 30.00 & $5.00-60.00$ & \\
\hline \multirow{3}{*}{$\begin{array}{l}\text { Post Intervention } \\
\text { Knowledge }\end{array}$} & Conventional & 30 & 35.00 & $10.00-50.00$ & $<0.001$ \\
\hline & Semi SBL & 30 & 27.50 & $10.00-45.00$ & \\
\hline & Full SBL & 30 & 40.00 & $25.00-65.00$ & \\
\hline \multirow{3}{*}{$\begin{array}{l}\text { Knowledge } \\
\text { Difference }\end{array}$} & Conventional & 30 & 0.00 & $-30.00-20.00$ & $<0.001$ \\
\hline & Semi SBL & 30 & 0.00 & $-30.00-20.00$ & \\
\hline & Full SBL & 30 & 10.00 & $-10.00-40.00$ & \\
\hline \multirow{3}{*}{$\begin{array}{c}\text { Pre Intervention } \\
\text { Motivation }\end{array}$} & Conventional & 30 & 70.86 & $58.29-80.57$ & $<0.001$ \\
\hline & Semi SBL & 30 & 30.00 & $10.00-55.00$ & \\
\hline & Full SBL & 30 & 40.00 & $20.00-72,57$ & \\
\hline \multirow{3}{*}{$\begin{array}{l}\text { Post Intervention } \\
\text { Motivation }\end{array}$} & Conventional & 30 & 73.00 & $64.00-82.00$ & 0.303 \\
\hline & Semi SBL & 30 & 73.33 & $66.00-86,67$ & \\
\hline & Full SBL & 30 & 74.67 & $68.00-92.00$ & \\
\hline \multirow{3}{*}{$\begin{array}{l}\text { Motivation } \\
\text { Difference }\end{array}$} & Conventional & 30 & 4.85 & $-13,24-13,04$ & $<0.001$ \\
\hline & Semi SBL & 30 & 43.16 & $17.33-64.00$ & \\
\hline & Full SBL & 30 & 33.16 & $1.53-71.33$ & \\
\hline \multirow{3}{*}{$\begin{array}{c}\text { Pre Intervention } \\
\text { Clinical Skills }\end{array}$} & Conventional & 30 & 45.00 & $22.00-67.00$ & 0.010 \\
\hline & Semi SBL & 30 & 42.50 & $24.00-60.00$ & \\
\hline & Full SBL & 30 & 32.50 & $12.00-65.00$ & \\
\hline \multirow{3}{*}{$\begin{array}{l}\text { Post Intervention } \\
\text { Clinical Skills }\end{array}$} & Conventional & 30 & 76.00 & $70.00-81.00$ & $<0.001$ \\
\hline & Semi SBL & 30 & 56.50 & $34.00-76.00$ & \\
\hline & Full SBL & 30 & 79.00 & $76.00-84.00$ & \\
\hline \multirow{3}{*}{$\begin{array}{l}\text { Clinical Skills } \\
\text { Difference }\end{array}$} & Conventional & 30 & 30.00 & $3.00-55.00$ & $<0.001$ \\
\hline & Semi SBL & 30 & 16.50 & $-12.00-41.00$ & \\
\hline & Full SBL & 30 & 48.00 & $17.00-65.00$ & \\
\hline
\end{tabular}

Remarks $^{*}$ Kruskal Wallis test.

models could improve the students' knowledge, however, the Full SBL model was more effective than the Semi SBL model and Conventional model. In addition, Semi SBL was more effective in improving knowledge compared to the Conventional model. The result of this study was in line with a previous study, in which all students' knowledge [27] and skills were improved after simulation activities [8] [16]. There was a significant difference between pre-test and post-test values on critical thinking skills of nursing students between SBL 
Table 2. Post Hoc test with Mann Whitney test for comparative knowledge, motivation, inter-group clinical skills (full-SBL, semi-SBL and conventional) of the students of nursing about DKA management.

\begin{tabular}{cccc}
\hline \multirow{2}{*}{ Variable } & \multicolumn{3}{c}{ Learning Model } \\
\cline { 2 - 4 } & $\begin{array}{c}\text { Full SBL versus } \\
\text { Conventional }\end{array}$ & $\begin{array}{c}\text { Semi SBL versus } \\
\text { Conventional }\end{array}$ & $\begin{array}{c}\text { Semi SBL versus } \\
\text { Full SBL }\end{array}$ \\
\hline Post Intervention Knowledge & $<0.001$ & 0.053 & $<0.001$ \\
Knowledge Difference & 0.001 & 0.934 & $<0.001$ \\
Pre Intervention Motivation & $<0.001$ & $<0.001$ & 0.009 \\
Motivation Difference & $<0.001$ & $<0.001$ & 0.015 \\
Pre Intervention Clinical skills & 0.001 & 0.302 & 0.002 \\
Post Intervention Clinical skills & $<0.001$ & $<0.001$ & $<0.001$ \\
Clinical skills Difference & $<0.001$ & $<0.001$ & $<0.001$ \\
\hline
\end{tabular}

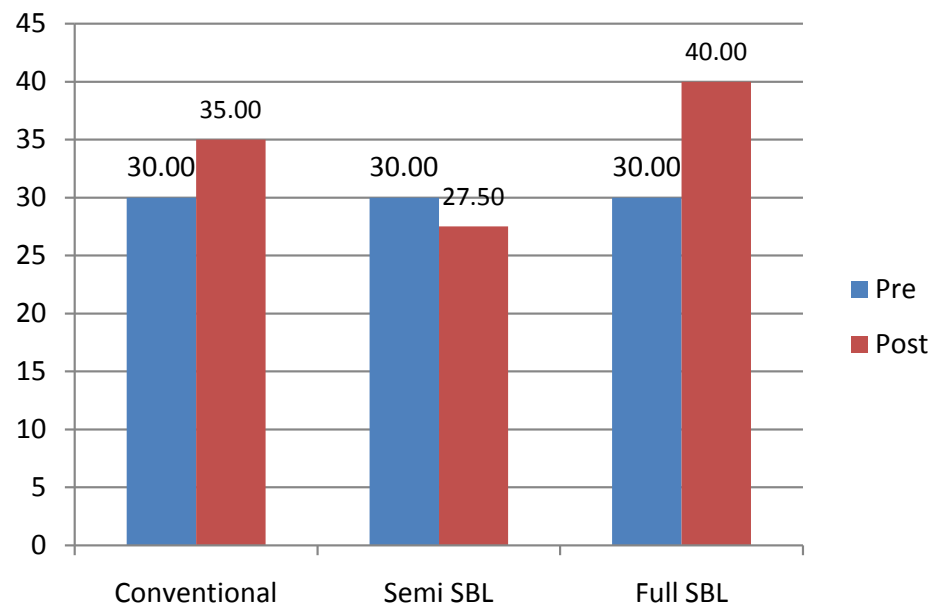

Figure 1. Chart on knowledge difference of the students of nursing who were given learning on full-SBL model group, semi-SBL model group and conventional model group.

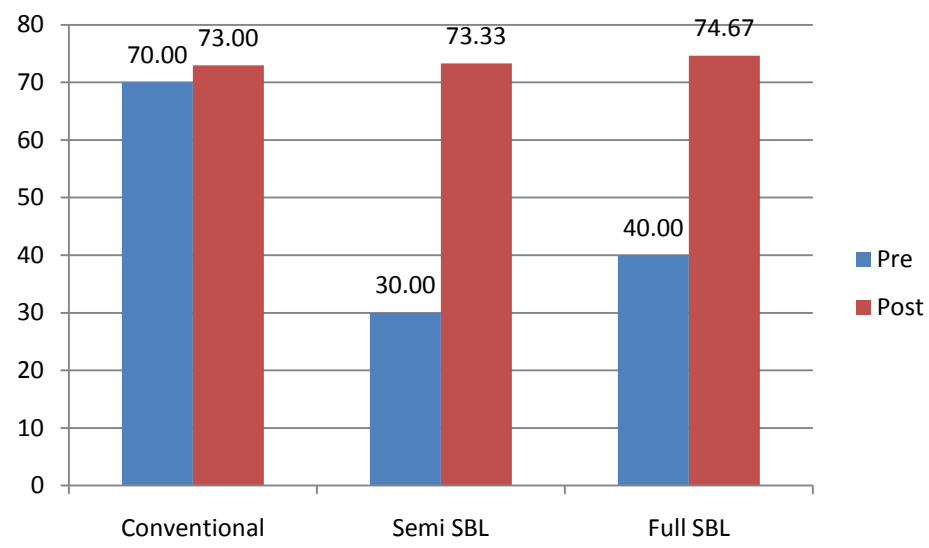

Figure 2. Chart on motivation difference of the students of nursing who were given learning on full-SBL model group, semi-SBL model group and conventional model group. 


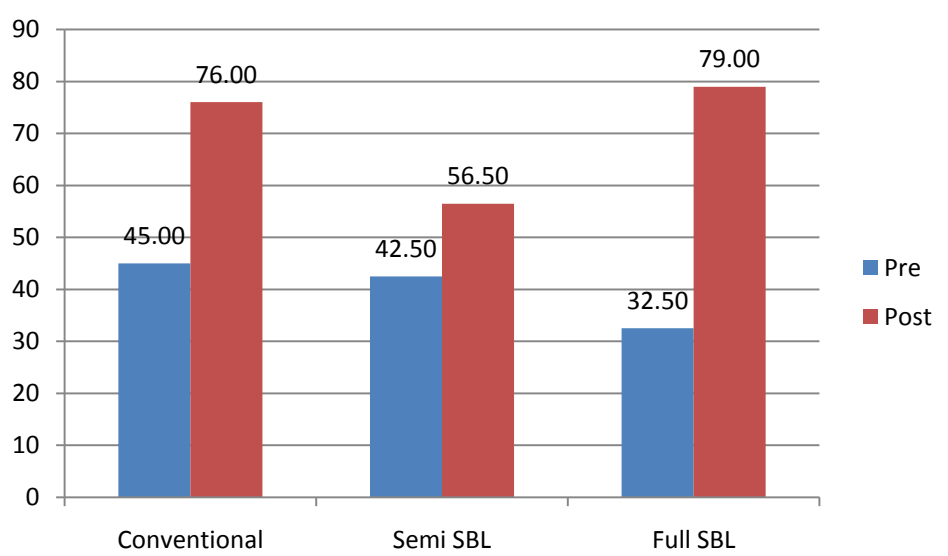

Figure 3. Chart on clinical competence difference of the students of nursing who were given lessons on the SBL-Full model group, semi-SBL model group and conventional model group.

groups and Conventional groups, meaning that there was a better effect to the critical thinking skills of nursing students with the SBL [8] [15]. The simulation learning model did not only improve the skills but also the knowledge [11]. Simulations as a practical learning model that develops both students cognitive and skill aspects. Learning by moving a real situation into learning activities due to difficulties or limitations to practice in real situations, Simulation is a reproduction of a situation based on a real-life picture [11].

\subsection{The Influence of Full SBL, Semi-SBL and Conventional Learning Model on the Motivation Improvement of the Nursing Students}

The research result shows that there was a better motivation by giving Full SBL Learning model compared to Semi-SBL and Conventional model (knowledge (74.67 vs. 73,33 vs. 73.00 ). The three models could improve student's learning motivation, however Full SBL model was more effective than Semi SBL and Conventional model. In addition, the semi-SBL model was more effective than the conventional in improving student's learning motivation [10] [11].

The three models showed an increase in motivation, although in the end, the full SBL model was more effective than the semi-SBL model and the conventional model. Motivation is a basic component in a person to do a job or activity in order to achieve an optimal result. In terms of learning, motivation is an intrinsic factor that greatly affects the success of students' learning. In a learning system centralized on students, student motivation becomes the key of success in the learning process because the objective and learning strategy in SBL model is built on the basis of awareness of the need to grow into student learning motivation [10]. High motivation leading to optimal learning behavior will be triggered? Characterized by a conscious desire to undertake learning activities that are not limited by time and place, Learning motivation refers to a strong desire for a person to learn further, studying various sources so that learning objectives 
are achieved [10] [13]. This study showed that motivation factor became the most important factor in clinical skill-based learning, especially in Bandung. The use of SBL model in practice learning could give a better result than the existing condition.

\subsection{The Influence of Full SBL, Semi-SBL and Conventional Learning Model to the Clinical Competence Improvement of the Nursing Students}

The research result showed that there was a better clinical competence with the provision of a full SBL learning model compared to Semi SBL and Conventional model (79.00 vs. 56.50 vs. 76.00$)$. The result of this study was in line with a prior study which explains that students who got simulation-based learning models could feel the benefit because they can learn a lot and can get a high level of confidence [6] [7] and satisfaction [8]. Simulation using High Fidelity Patient Simulator (HFPS) scenario could also practice collaboration between the nurse and the physician in treating the patient and in making the decision on the management of patients [28] [29]. The result of this study was also in line with a previous study which explains that the simulation method significantly influences the increase in the ability of bedside skill of nursing students compared to those who studied in the conventional way [8]. Simulation Model is very influential in improving the practice skills and knowledge in ICU room [9]. Human patient simulators are used for teaching higher level skills, such as airway management [8].

The existence of educational indications with simulations showed an influence in guiding education nurses with simulated patients, which was more effective than the traditional learning models [10]. In addition, the knowledge and skills of all students increased after following the simulation activities [8].

Furthermore, there was a significant difference in pre-test and posttest average value in nursing students' critical thinking skill between SBL group learning and Partial Task Trainer, meaning there was a significant influence of Simulation-Based Learning (SBL) model that is better towards the critical thinking skills of nursing students [8] [10]. There was a significant increase in students' critical thinking $(p<0.001)$. Metacognitive awareness was better after the implementation of SBL model [29].

The effectiveness of the full SBL model was supported by the implementation of systematic learning stages in accordance with the rules and correct simulated learning model as well as the presence of trained facilitators who master the learning substance well. The simulation learning model has advantages in sharpening the internalization of learning materials to the students by bringing together various sensory stimuli into the learning activities.

In the view of neuroscience, these learning outcomes can be analyzed as the process that occurs in the brain where the visual or auditoric sensations in a person in the form of information are followed by practicing directly and are perceived by the cerebral cortex through the hippocampus as a stored informa- 
tion [30]. Hippocampus then translates some of these signals from short-term memory to long-term memory, so that it is stored in the brain as information that can last for a longer time. When that happens, the brain will be better trained for newly acquired information up to permanent storage in the brain. Based on that, someone who practices something directly will be better at remembering the information it gets for a long time [11] [30].

\section{Conclusions}

The result of the research showed that the effectiveness of Human Patient Simulator towards the improvement of Knowledge, Motivation, and Clinical Competence of the Nursing students. In addition, the research found that Human Patient Simulator (Full Simulation-Based Learning) was better in improving Knowledge, Motivation and Clinical competence of the Nursing students on Diabetic Ketoacidosis Management compared to Semi Simulation-Based Learning (Semi SBL) and Conventional model.

To improve the competence of nursing education graduates in Indonesia, further research is needed on the implementation of Learning-Based Simulation Learning (SBL) with HPS on other clinical competence learning.

\section{Conflicts of Interest}

The authors declare no conflicts of interest regarding the publication of this paper.

\section{References}

[1] Addison, R., Skinner, T., Zhou, F. and Parson, M. (2017) Diabetic Ketoacidosis: An Emergency Medicine Simulation Scenario. Cureus, 9, e1286.

[2] Deeb, A., Yousef, H., Abdelrahman, L., Tomy, M., Suliman, S., Attia, S., et al. (2016) Implementation of a Diabetes Educator Care Model to Reduce Paediatric Admission for Diabetic Ketoacidosis. Journal of Diabetes Research, 2016, Article ID: 3917806.

[3] Tran, T.T.T., Pease, A., Wood, A.J., Zajac, J.D., Mårtensson, J., Bellomo, R. and Ekinci, E. (2017) Review of Evidence for Adult Diabetic Ketoacidosis Management Protocols. Frontiers in Endocrinology, 8, 106. https://doi.org/10.3389/fendo.2017.00106

[4] Aebersold, M. and Tschannen, D. (2013) Simulation in Nursing Practice: The Impact on Patient Care, OJIN: The Online Journal of Issues in Nursing, 18, 6.

[5] Nursing Program Poltekkes Kemenkes Bandung, Diploma III Nursing Curriculum Year 2014. 4-6.

[6] Lapkin, S., Fernandez, R., Levett-Jones, T. and Bellchambers, H. (2010) The Effectiveness of Using Human Patient Simulation Manikins in the Teaching of Clinical Reasoning Skills to Undergraduate Nursing Students: A Systematic Review. JBI Library of Systematic Reviews, 8, 661-694. https://www.ncbi.nlm.nih.gov/pubmed/27820553

[7] Lee, A.H., Kelley, C., Alfes, C.M., Bennington, L.K. and Dolansky, M.A. (2017) High-Fidelity Patient Simulation to Evaluate Student Nurse Patient Safety Competency. Clinical Simulation in Nursing, 13, 628-633. 
https://doi.org/10.1016/j.ecns.2017.08.006

[8] Laschinger, S., Medves, J., Pulling, C., McGraw, R., Waytuck, B., Harrison, B.M., et al. (2008) Effectiveness of Simulation on Health Profession Students' Knowledge, Skills, Confidence and Satisfaction. International Journal of Evidence-Based Healthcare, 6, 278-302. https://www.ncbi.nlm.nih.gov/pubmed/21631826 https://doi.org/10.1111/j.1744-1609.2008.00108.x

[9] Schroedl, C.J., Corbridge, T.C., Cohen, E.R., Fakhran, S.S., Schimmel, D., McGaghie, W.C., et al. (2012) Use of Simulation-Based Education to Improve Resident Learning and Patient Care in the Medical Intensive Care Unit: A Randomized Trial. Journal of Critical Care, 27, e7-e13, https://doi.org/10.1016/j.jcrc.2011.08.006

[10] Sportsman, S., Schumacker, R.E. and Hamilton, P. (2011) Evaluating the Impact of SCENARIO-Based High-Fidelity Patient Simulation on Academic Metrics of Student Success. Nursing Education Perspectives, 32, 259-265.

https://www.ncbi.nlm.nih.gov/pubmed/21923008 https://doi.org/10.5480/1536-5026-32.4.259

[11] Lateef, F. (2010) Simulation-Based Learning: Just Like the Real Thing. Journal of Emergencies, Trauma and Shock, 3, 348-352. https://doi.org/10.4103/0974-2700.70743

[12] Nehring, W.M., Ellis, W.E. and Lashley, F.R. (2001) Human Patient Simulators in Nursing Education: An Overview. Simulation \& Gaming, Symposium on Medical and Healthcare Simulation, 32, 194-204.

https://dl.acm.org/citation.cfm?id=380281

[13] Cant, R.P. and Cooper, S.J. (2010) Simulation-Based Learning in Nurse Education: Systematic Review. Journal of Advanced Nursing, 66, 3-15.

https://www.ncbi.nlm.nih.gov/pubmed/20423432 https://doi.org/10.1111/j.1365-2648.2009.05240.x

[14] Ruth, M. and Fanning, D.M.G. (2007) The Role of Debriefing in Simulation-Based Learning. Review Article: Simulation in Healthcare, 2, 115-125. https://doi.org/10.1097/SIH.0b013e3180315539

[15] Lasater, K. (2007) High-Fidelity Simulation and the Development of Clinical Judgment: Students' Experiences. Journal of Nursing Education, 46, 267-276. https://www.ncbi.nlm.nih.gov/pubmed/17580739

[16] Murray, C., Grant, M.J., Howarth, M.L. and Leigh, J. (2008) The Use of Simulation as a Teaching and Learning Approach to Support Practice Learning. Nurse Education in Practice, 8, 5-8. https://doi.org/10.1016/j.nepr.2007.08.001

[17] Wilford, A. and Doyle, T.J. (2006) Integrating Simulation Training into the Nursing Curriculum. British Journal of Nursing, 15, 926-930. https://doi.org/10.12968/bjon.2006.15.17.21907

[18] Beigzadeh, A., Bahmanbijari, B., Sharifpoor, E. and Rahimi, M. (2016) Standardized Patients versus Simulated Patients in Medical Education: Are They the Same or Different. Journal of Emergency Practice and Trauma Short Communication, 2, 25-28.

[19] PB Perkeni (2014) Konsensus Pengelolaan dan Pencegahan Diabetes Mellitus Tipe 2 di Indonesia. http://pbperkeni.or.id/newperkeni/panduan-guideline/

[20] Gotera, W. and Budiyasa, D.G.A. (2012) Penatalaksanaan Ketoasidosis Diabetik (KAD). Journal of Internal Medicine, 11, 126-138. https://ojs.unud.ac.id/index.php/jim/article/view/3948

[21] Chan, J.C., Malik, V., Jia, W., Kadowaki, T., Chittaranjan, S., Yajnik, et al. (2009) Diabetes in Asia: Epidemiology, Risk Factors, and Pathophysiology. JAMA, 301, 
2129-2140. https://doi.org/10.1001/jama.2009.726

[22] Van Zyl, D.G. (2008) Diagnosis and Treatment of Diabetic Ketoacidosis: CPD. South African Family Practice, 50, 35-39.

https://www.tandfonline.com/doi/abs/10.1080/20786204.2008.10873664 https://doi.org/10.1080/20786204.2008.10873664

[23] Tuan, H.L., Chin, C.C. and Shieh, S.H. (2005) The Development of a Questionnaire to Measure Students' Motivation towards Science Learning. International Journal of Science Education, 27, 639-654. https://doi.org/10.1080/0950069042000323737

[24] American Diabetes Association (2008) Standards of Medical Care in Diabetes-2008. Diabetes Care, 31, S12-S54, https://doi.org/10.2337/dc08-S012

[25] Handelsman, Y., Bloomgarden, Z.T., Grunberger, G., Umpierrez, G., Zimmerman, Timothy R.S., Bailey, S., et al. (2015) American Association of Clinical Endocrinologists And American College Of Endocrinology-Clinical Practice Guidelines For Developing A Diabetes Mellitus Comprehensive Care Plan-2015. Endocrine Practice, 21, 413-437. https://www.aace.com/files/dm-guidelines-ccp.pdf https://doi.org/10.4158/EP15672.GL

[26] Devalia, B. (2010) Adherance to Protocol during the Acute Management of Diabetic Ketoacidosis: Would Specialist Involvement Lead to Better Outcomes? International Journal of Clinical Practice, 64, 1580-1582. https://doi.org/10.1111/j.1742-1241.2010.02348.x

[27] Cortegiani, A., Russotto, V., Montalto, F., Iozzo, P., Palmeri, C., Raineri, S.M., et al. (2015) Effect of High-Fidelity Simulation on Medical Students' Knowledge about Advanced Life Support: A Randomized Study, PLOS ONE, 10, e0125685. https://doi.org/10.1371/journal.pone.0125685

[28] Maxson, P.M., Dozois, E.J., Holubar, S.D., Wrobleski, D.M., Dube, J.A., Klipfel, J.M., et al. (2011) Enhancing Nurse and Physician Collaboration in Clinical Decision Making through High-Fidelity Interdisciplinary Simulation Training. Mayo Clinic Proceedings, 86, 31-36. https://doi.org/10.4065/mcp.2010.0282

[29] Oh, P.J., Jeon, K.D. and Koh, M.S. (2015) The Effects of Simulation-Based Learning Using Standardized Patients in Nursing Students: A Meta-Analysis. Nurse Education Today, 35, e6-e15. https://doi.org/10.1016/j.nedt.2015.01.019

[30] Ackerman, S. (1992) Learning, Recalling, and Thinking. In: Discovering the Brain, National Academies Press, Washington DC. https://www.ncbi.nlm.nih.gov/books/NBK234153/

\section{Appendix}

SBL: Simulation based learning

DKA: Diabetic Ketoacidosis

HPS: Human Patient Simulator

SMTSL: Students'motivation toward science learning 